Review Article

\title{
The Comparison of Short-Term Postoperative Pain in Single- versus Multiple-Visit Root Canal Treatment: A Systematic Review and Meta-Analysis Study
}

\author{
Armin Izadpanah $\left(\mathbb{D},{ }^{1}\right.$ Ailar Javaheripour $\left(\mathbb{D},{ }^{1}\right.$ Azam Maleki $\left(\mathbb{D},{ }^{2}\right.$ Mahdieh Alipour $\left(\mathbb{D},{ }^{3}\right.$ \\ Hossein Hosseinifard $\left(\mathbb{0},{ }^{4}\right.$ Simin Sharifi $(1)^{3},{ }^{3}$ and Solmaz Maleki Dizaj $\mathbb{1}^{3}$ \\ ${ }^{1}$ Faculty of Dentistry, Tabriz University of Medical Sciences, Tabriz, Iran \\ ${ }^{2}$ Social Determinants of Health Research Center, Zanjan University of Medical Sciences, Zanjan, Iran \\ ${ }^{3}$ Dental and Periodontal Research Center, Faculty of Dentistry, Tabriz University of Medical Sciences, Tabriz, Iran \\ ${ }^{4}$ Department of Biostatistics, Faculty of Paramedical Sciences, Shahid Beheshti University of Medical Sciences, Tehran, Iran
}

Correspondence should be addressed to Simin Sharifi; sharifi.ghazi@gmail.com and Solmaz Maleki Dizaj; maleki.s.89@gmail.com

Received 15 January 2021; Accepted 31 March 2021; Published 10 April 2021

Academic Editor: Xue-Qiang Wang

Copyright (c) 2021 Armin Izadpanah et al. This is an open access article distributed under the Creative Commons Attribution License, which permits unrestricted use, distribution, and reproduction in any medium, provided the original work is properly cited.

\begin{abstract}
Postoperative pain after root canal therapy (RoCT) is an unpleasant experience for patients, and it could be affected by different factors. The times of visits could be one of these factors that were evaluated in various studies. However, there is inconsistent evidence on the relation between postoperative pain and the times of visits. Therefore, the current systematic review aimed to summarize the results of these studies and meta-analyze them. For this purpose, a comprehensive search was conducted in four main databases (Cochrane Database of Systematic Reviews, Web of Science, PubMed, and Scopus databases) for related English articles from 1978 to August 2020. The quality of studies was evaluated using the Delphi checklist. The heterogeneity of studies was determined by $I^{2}$ statistic, and publication bias was assessed using the funnel plot and the Begg test. The results were presented by using relative ratio (RR) estimates and standard mean difference (SMD) with its $95 \%$ confidence intervals (CI) using a randomeffects model. Initial searches from mentioned databases identified 1480 papers; of which only 27 of them met the inclusion criteria. In quality assessment, thirteen studies had quality scores of more than 7, two studies had 4 scores, and the rest had 5 scores. Overall, based on the available evidence, the meta-analysis showed that the risk of postoperative pain in single-visit was 1.02 times (CI 95\% $\left.(0.99,1.19), I^{2}=60.7 \%, p=0.001\right)$ higher than that of the multiple-visit treatment. The mean difference of postoperative pain in single-visit was -0.30 (CI 95\% $\left.(-0.36,-0.25), I^{2}=0.94 .4, p=0.001\right)$ compared with the multiple-visit treatment. Based on the results of this meta-analysis, the risk of postoperative pain in single-visit RoCT was higher than that in multiple-visit RoCT with acceptable statistical heterogeneity and moderate quality of the studies.
\end{abstract}

\section{Introduction}

Root canal treatment (RoCT) is a common procedure in dentistry to the treatment of infected and traumatized teeth in order to save the integrity of patients' occlusion. The necrosis of the dental pulp and irreversible pulpitis are the main indications for RoCT that are caused by dental caries, the cracks or chips of the tooth, or dental trauma. Root canal treatment is necessary to avoid tooth extraction and to relieve symptoms due to complications following necrosis of the dental pulp. One of the important steps of root canal treatment is shaping and cleaning. In this stage, all organic particle debris and inorganic material remaining in the root canal of the tooth are cleaned for adaptation of root canal filling materials to the canal completely $[1,2]$.

One-visit root canal treatment is a common procedure, which has some benefits both for dentists and their patients including a reduced number of visits, postoperative flareups, chair-side time, and increased patient acceptance. Multiple-visit endodontic is another routine treatment in 
which researchers can place intracanal medicaments such as chlorhexidine and calcium hydroxide [3].

The rate of postendodontic pain among patients ranged between $25 \%$ and $58 \%$ of all endodontic patients [4]. Patients can exaggerate their memory of the pain of previous treatment and cause dental fear and anxiety $[5,6]$. Due to the low cooperation of the anxious patients, the dentist requires spending more time and resources on treatment of them, which is an unpleasant experience for both patients and clinicians [7, 8]. Moreover, the postendodontic pain could affect the patient's quality of life and daily functions after treatment [9]. Therefore, the reduction in postoperative pain experience of patients is considered one of the most important aspects of clinical practice [6].

Postoperative pain is a multifactorial phenomenon, which depends on pretreatment, intratreatment, and posttreatment factors such as preoperative pain, intracanal medications, and analgesic administration. Therefore, the clinician could optimize the treatment procedures in different stages to control postendodontic pain $[4,10]$. The effect of visit number on postendodontic pain is one of the intratreatment factors, which has been studied in different studies. However, the results of these studies were not consistent [11-13].

Moreover, there are limited reviews that studied the postendodontic pain in single- or multiple-visit treatments. However, their results were not performed subgroup analysis based on the type of study, or they were derived from both randomized and nonrandomized studies and the number of included articles was limited [14, 15]. Therefore, due to the lack of consistency in these studies, we applied a meta-analysis of randomized controlled trials (RCTs) to compare the short-term postendodontic pain in one- versus multiple-visit root canal treatment. The aim of the current study was to investigate whether completion of root canal treatment (RoCT) of permanent teeth in one visit or multiple visits makes any difference in short-term postoperative pain.

\section{Materials and Methods}

2.1. Search Strategy and Data Sources. This meta-analysis was performed and reported in adherence with Preferred Reporting Items for Systematic Reviews and Meta-analysis. The Cochrane Database of Systematic Reviews, Web of Science, PubMed, and Scopus databases were systematically searched for English language studies published from 1978 to August 2020 using the following search strategies in accordance with the MeSH browser keywords and free-text words. After searching the databases, some recognized journals in this field including the International Endodontic Journal and Journal of Endodontics were also hand-searched. In addition, the reference list of identified studies and related systematic reviews was checked. We contacted the authors if required to obtain the full texts of the study.

We used a search strategy, which has been developed in MEDLINE and adapted for other databases. Keywords were extracted from the MeSH terms and were used in various combinations as follow:
Root Canal Obturation, Endodontic Obturation, root canal treatment, root canal therapy, dental pulp capping, pulpectomy, single, first, 1st, one, multiple, second, 2nd, two, visit, appointment, session, pain, randomized controlled trial, controlled clinical trial, random allocation, double blind method, single-blind method, clinical trial.

2.2. Study Selection. Two authors (A.I. and A.J.) independently searched and screened the titles, abstracts, and full texts of the extracted studies in EndNote X8. The duplicates were also removed. Disagreements of the extractors were resolved by discussion with a third person.

2.3. Eligibility Criteria. The studies that met the following criteria were included: randomized controlled trials (RCTs) with at least two groups (control and intervention) that aimed to measure short-term (up to 7 days) follow-up postoperative pain, root canal treatment (RoCT) of permanent teeth, and healthy people aged more than 10 years. The visual analog scale (VAS) was used to measure the pain [16].

2.4. Exclusion Criteria. The trials have been carried out on participants with systemic disease, aged less than 10 years, having acute apical abscesses, using antibiotics or corticosteroids 3 months ago, and having multiple teeth that increasing the opportunity of referral pain; quasiexperimental, meta-analysis, cross-sectional, and observational studies were also included.

2.5. Data Collection Process. After providing the full texts of the included studies, data extraction was performed using a structured form including author name, published year, location, type of the study, sample size, age range, follow-up duration, irrigation solution, obturation method, and study quality.

2.6. Outcomes. In this study, the main outcome was postendodontic pain and the subgroup analysis was carried out based on vital and nonvital pulps and follow-up times.

2.7. Risk of Bias in Individual Studies. The Delphi checklist has been used for the evaluation of quality and risk of bias in individual studies [17]. The checklist includes 9 questions. Each item gets a score when it will be appropriate criteria. Therefore, a maximum score of nine was allocated to each study.

2.8. Synthesis of Results. STATA software, version 16, was used for analyses. Mean difference and the relative risk were used to find the effect for continuous and dichotomous data, respectively. The heterogeneity of the studies was assessed using $I$ squared statistic. Heterogeneity less than $70 \%$ was considered acceptable. We presented results using relative ratio (RR) estimates and standard mean difference (SMD) with its $95 \%$ 


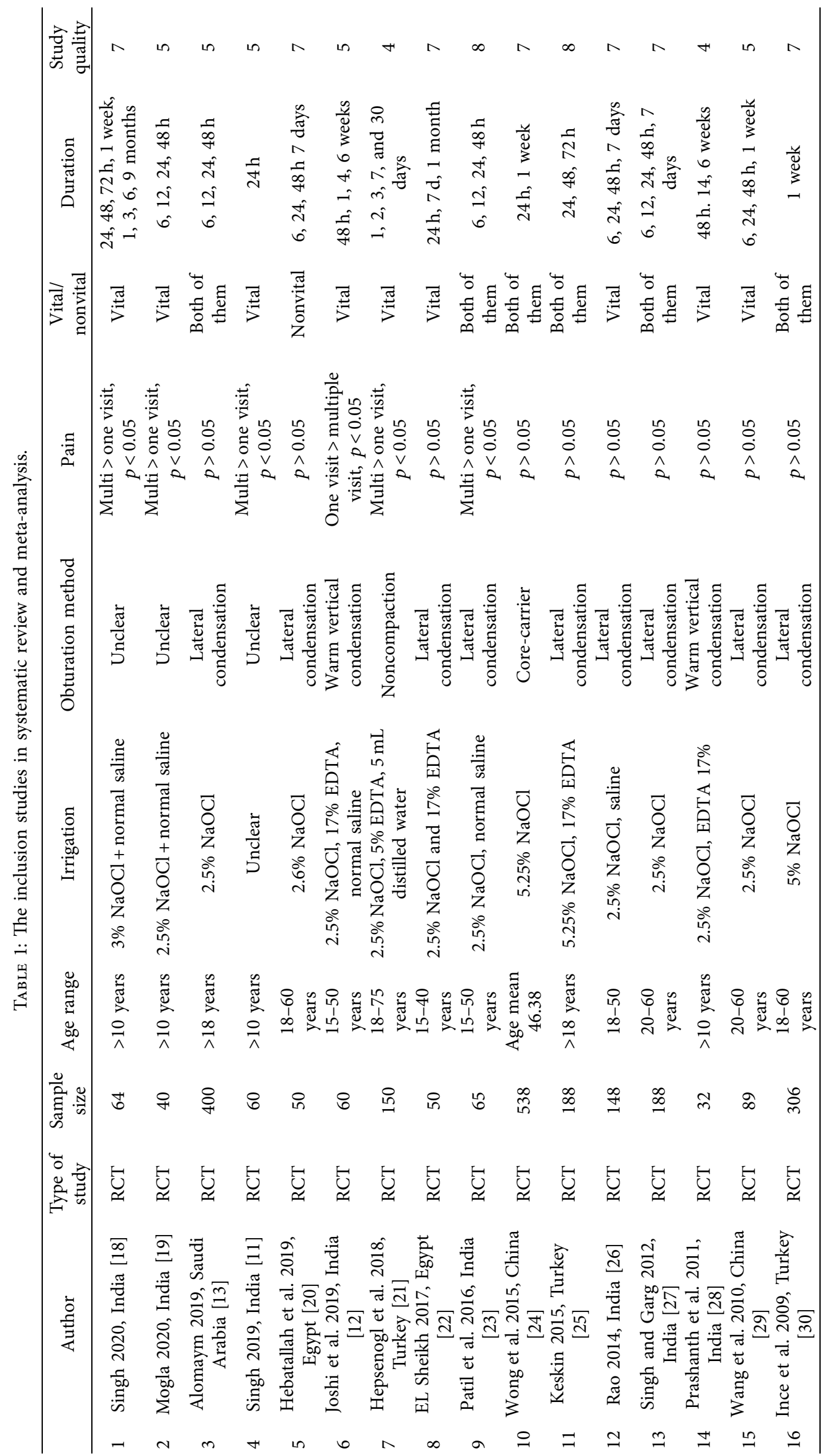




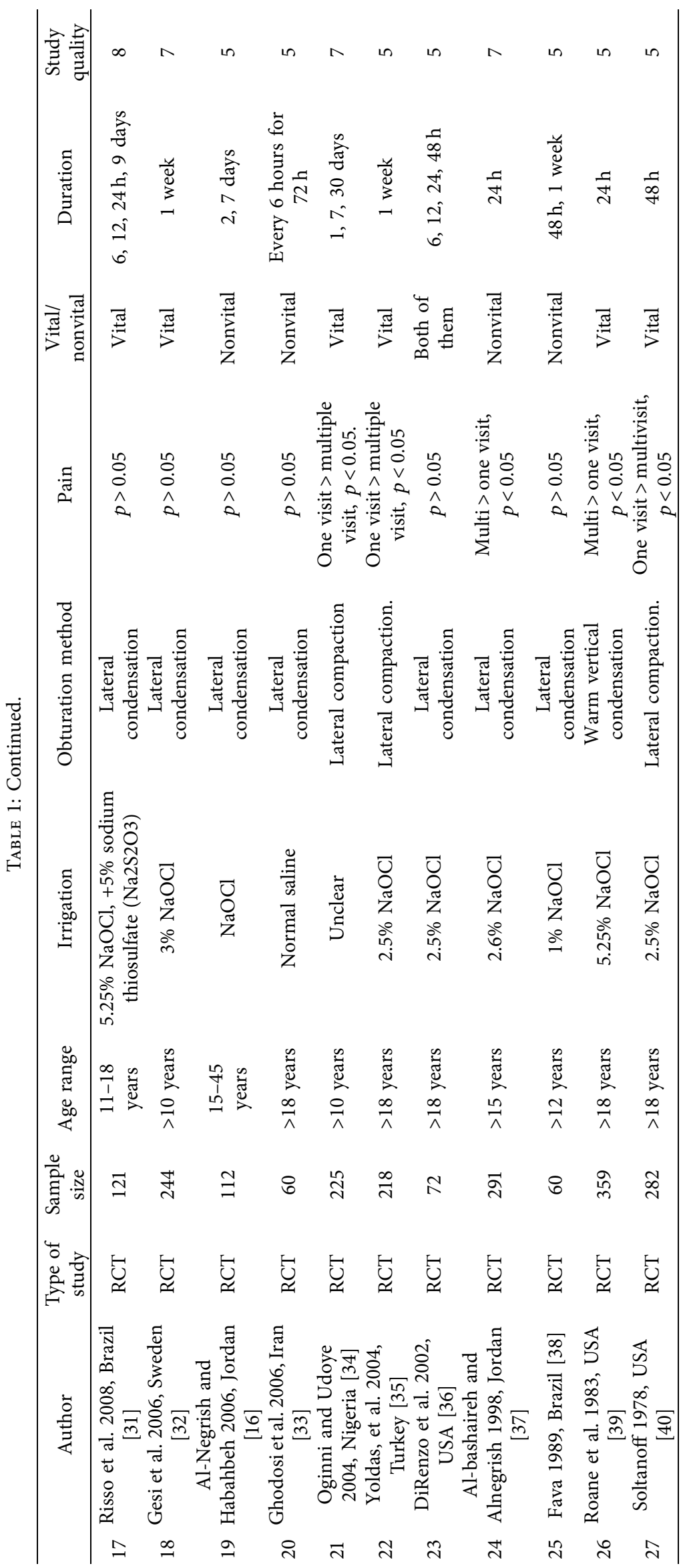




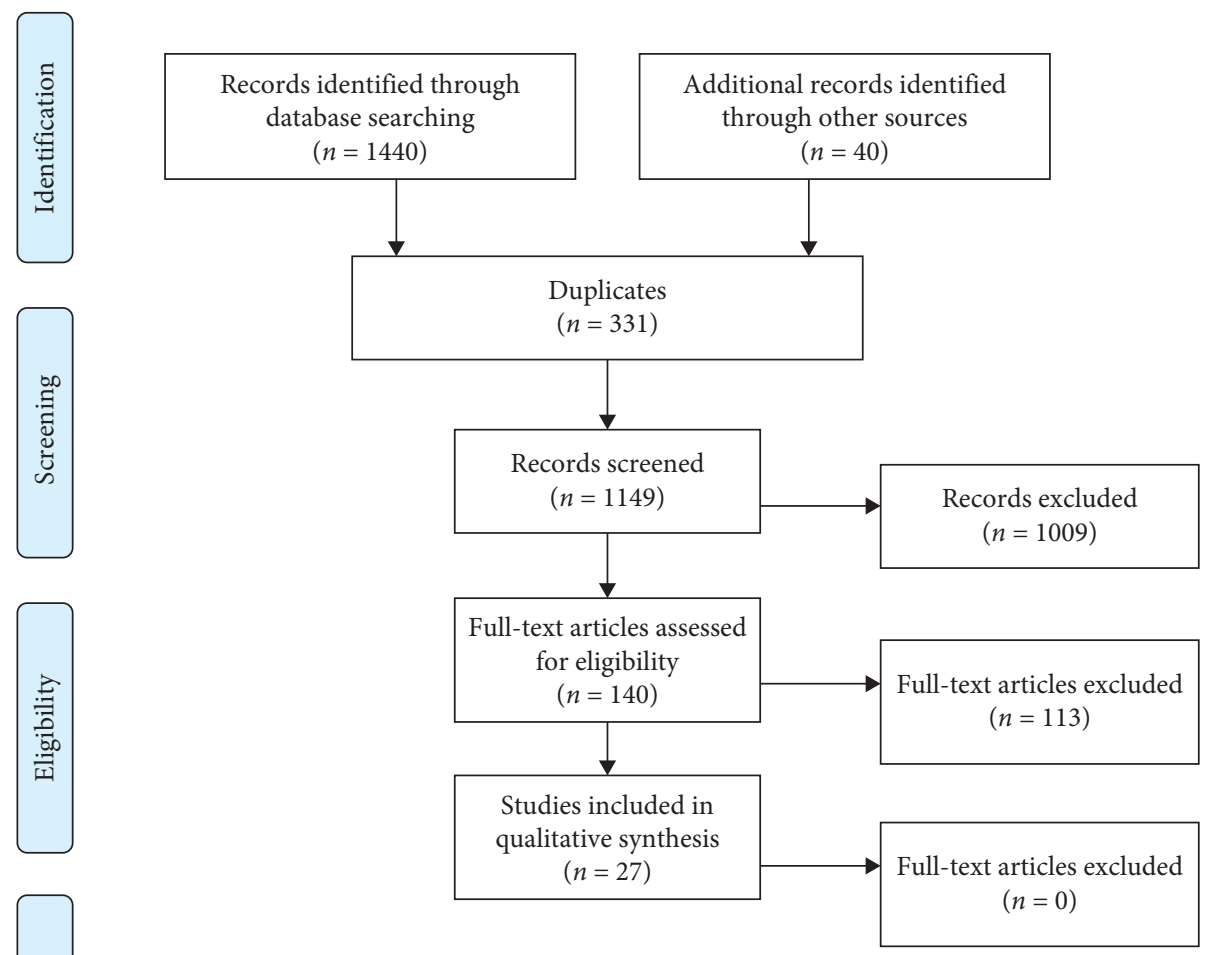

Figure 1: A flowchart of the extracted articles and selection procedure.

confidence intervals (CI) using a random-effects model. The subgroup analysis was carried out based on the follow-up duration and vitality of the root canal. Publication bias was assessed using the funnel plot and the Begg test.

\section{Results}

3.1. Study Selection. A total of 1480 studies were extracted in the primary search based on the search strategy to August 2020; three hundred thirty-one duplicate studies, 1009 studies after the title and abstract review, and finally 113 studies after the full-text review were excluded.

A total of 27 studies with 4472 subjects met the inclusion criteria were retrieved in this review (Table 1). All extracted studies were published in English language. A flowchart of the extracted studies and selection procedure is shown in Figure 1.

3.2. Study Characteristics. The results of the included studies are shown in Table 1 . From the 27 included studies, eight studies were conducted in India, three studies were in the United States, and four studies in Turkey. Four studies (one study each) were carried out in Saudi Arabia, Iran, Nigeria, and Sweden, and eight studies (2 studies each) were carried out in Egypt, Jordan, Brazil, and China. From the 27 included studies, in 16 studies, the incidence of postoperative pain was not significant, whereas it was significant in 11 studies. In seven of the 11 studies, the pain incidence of multiplevisit treatment was significantly higher than that of a single visit, and in the remaining four studies, this result was inconsistent. The minimum follow-up period was 6 hours, and the maximum was 9 months, but in the present study, follow-up for up to 7 days was considered for analysis. From the 27 included studies, in 15 studies, treatment was performed on a vital root canal, and the rest of the studies had at least one group of the nonvital root canal. From the 27 included studies, the irrigation solution in two studies was unclear; in one study, normal saline was used; and in the rest, hypochlorite $(\mathrm{NaOCl})$ was used for irrigation during root canal preparation. The obturation technique in three studies was unclear; in 19 studies, lateral compaction technique was used; in three studies, vertical compaction technique; in one study, noncompaction was used; and in one study, core-carrier compaction technique for obturation was used (Table 1).

3.3. Risk of Bias within Studies. In quality assessment, thirteen studies had quality scores of more than 7 , two studies had 4 , and the rest had 5 . None of the studies obtained a quality score of 9 (Table 1 ). 


\begin{tabular}{|c|c|c|}
\hline $\begin{array}{l}\text { Study } \\
\text { ID }\end{array}$ & $\mathrm{RR}(95 \% \mathrm{CI})$ & $\begin{array}{c}(\%) \\
\text { weight }\end{array}$ \\
\hline \multicolumn{3}{|l|}{$24 \mathrm{~h}$} \\
\hline Roare 1983 & $0.49(0.33,0.73)$ & 6.74 \\
\hline Hepsenoglu 2018 & $0.73(0.50,1.08)$ & 4.27 \\
\hline Wang 2010 & $1.01(0.83,1.24)$ & 5.09 \\
\hline Risso 2008 & $0.46(0.19,1.11)$ & 1.92 \\
\hline Oginni 2004 & $1.21(0.94,1.56)$ & 7.65 \\
\hline lnce 2009 & $0.89(0.70,1.14)$ & 10.67 \\
\hline Soltanof 1978 & $1.33(0.85,2.08)$ & 3.11 \\
\hline EL Sheikh 2017 & $0.57(0.16,2.01)$ & 0.79 \\
\hline Singh 2019 & $0.31(0.09,1.07)$ & 1.16 \\
\hline Subtotal $\left(I^{2}=68.8 \%, p=0.001\right)$ & $0.87(0.77,0.99)$ & 41.41 \\
\hline \multicolumn{3}{|l|}{$7 \mathrm{~d}$} \\
\hline Yoldas 2004 & $1.88(0.87,4.07)$ & 1.25 \\
\hline Soltanof 1978 & $1.47(1.12,1.91)$ & 6.38 \\
\hline Albashaireh 1998 & $0.73(0.52,1.02)$ & 7.78 \\
\hline Wong 2015 & $1.83(0.97,3.46)$ & 1.82 \\
\hline Joshi 2019 & $1.60(0.59,4.33)$ & 0.71 \\
\hline Hepsenoglu 2018 & $1.00(0.31,3.24)$ & 0.71 \\
\hline Oginni 2004 & $1.21(0.94,1.56)$ & 7.65 \\
\hline Wang 2010 & $1.40(0.78,2.52)$ & 1.79 \\
\hline Gesi 2006 & $1.72(0.79,3.76)$ & 1.30 \\
\hline AI-Negrish 2006 & $0.52(0.10,2.72)$ & 0.56 \\
\hline Luiz Roberto 1989 & $3.00(0.13,70.83)$ & 0.07 \\
\hline Wong 2015 & $1.83(0.97,3.46)$ & 1.82 \\
\hline EL Sheikh 2017 & $0.38(0.02,8.86)$ & 0.20 \\
\hline Subtotal $\left(I^{2}=33.7 \%, p=0.113\right)$ & $1.26(1.10,1.46)$ & 32.02 \\
\hline \multicolumn{3}{|l|}{$48 \mathrm{~h}$} \\
\hline Joshi 2019 & $1.75(0.86,3.55)$ & 1.14 \\
\hline Hepsenoglu 2018 & $0.52(0.32,0.84)$ & 4.13 \\
\hline Wang 2010 & $1.07(0.69,1.66)$ & 2.89 \\
\hline Prashanth 2011 & $2.00(0.20,19.91)$ & 0.14 \\
\hline AI-Negrish 2006 & $0.69(0.33,1.46)$ & 1.92 \\
\hline Luiz Roberto 1989 & $3.00(0.13,70.83)$ & 0.07 \\
\hline Subtotal $\left(I^{2}=52.3 \%, p=0.063\right)$ & $0.88(0.67,1.15)$ & 10.29 \\
\hline \multicolumn{3}{|l|}{$72 \mathrm{~h}$} \\
\hline Ince 2009 & $0.89(0.70,1.14)$ & 10.67 \\
\hline Ghoddusi 2004 & $0.89(0.43,1.83)$ & 1.28 \\
\hline Soltanof 1978 & $2.29(1.37,3.81)$ & 1.91 \\
\hline Hepsenoglu 2018 & $0.59(0.30,1.16)$ & 2.42 \\
\hline Subtotal $\left(I^{2}=77.6 \%, p=0.004\right)$ & $1.01(0.83,1.23)$ & 16.28 \\
\hline Overall $\left(I^{2}=60.7 \%, p=0.000\right)$ & $1.02(0.94,1.11)$ & 100.00 \\
\hline .0141 & 70.8 & \\
\hline
\end{tabular}

FIgURE 2: Forest plot of comparison pain in terms of follow-up time (dichotomous).

3.4. Synthesis of Results. The data of postoperative pain in 10 studies were reported as continuous data, and 17 studies, dichotomous data, which were analyzed separately.

Overall, on the basis of the available evidence, the metaanalysis showed that the risk of postoperative pain in one visit was 1.02 times (CI $0.99-1.19, I^{2}=60.7 \%, p=0.001$ ) higher than that in the multiple-visit treatment.

In follow-up period subgroup analysis, the relative risk of having pain at $24 \mathrm{~h}$ after single-visit treatment was 0.83 times (CI $0.65-1.06, I^{2}=68.8, p=0.001$ ) higher than that after multiple-visit treatment. Furthermore, the relative risk for 48-h follow-up period was 0.94 times (CI 0.58-1.48, $\left.I^{2}=52.3, p=0.06\right)$, for 72 -h follow-up period was 1.04 times (CI $0.61-1.76, I^{2}=77.6, p=0.004$ ), and for 7 -day follow-up period was 1.30 times (CI $0.88-1.18, I^{2}=32.7$, $p=0.113$ ) higher than that in the multiple-visit treatment (Figure 2).

In vital root canal subgroup analysis, the relative risk of having pain in single-visit was 1.05 times (CI 0.88-1.25, $\left.I^{2}=65.8, p=0.001\right)$ and in the nonvital group was 0.76 times (CI $0.57-1, I^{2}=0.00, p=0.856$ ) higher than that in the multiple-visit treatment (Figure 3). 


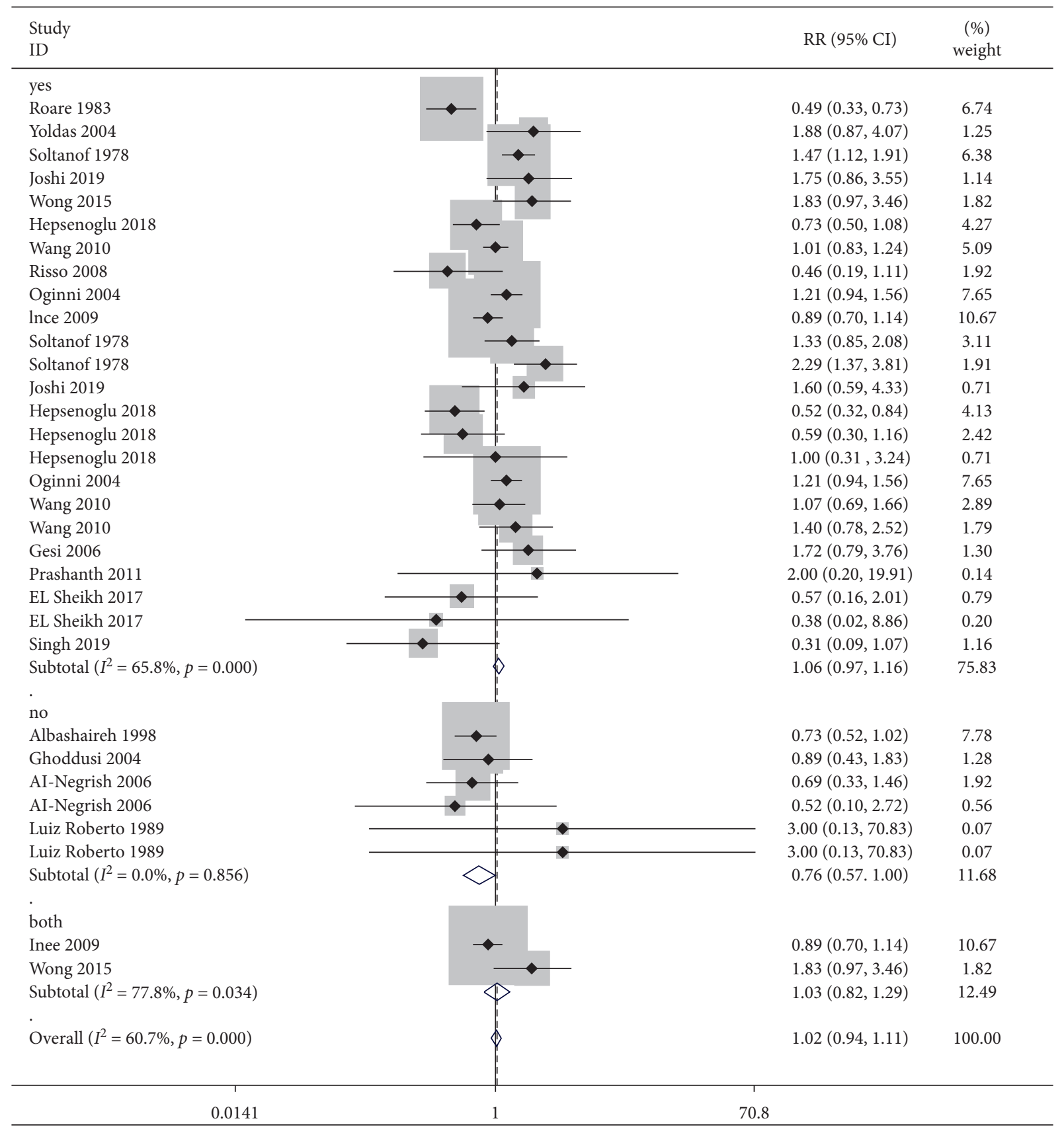

FIGURE 3: Forest plot of comparison pain in terms of vital/nonvital root canal (dichotomous).

The overall standardized mean difference (SMD) of postoperative pain in single-visit was -0.30 (CI $-0.36,-0.25$, $\left.I^{2}=0.94 .4, p=0.001\right)$ compared with that in the multiplevisit treatment. In follow-up period subgroup analysis, the SMD of single-visit treatment on pain after $6 \mathrm{~h}$ was -0.36 (CI $-0.49,0.23 ; I^{2}=84.6, p=0.001$ ), after $12 \mathrm{~h}$ was -0.41 (CI $\left.-0.54,-0.27 ; I^{2}=88.9, p=0.001\right)$, after $24 \mathrm{~h}$ was $-0.12(\mathrm{CI}$ $\left.-0.21,-0.03 ; I^{2}=90.7, p=0.001\right)$, after $48 \mathrm{~h}$ was $0.06(\mathrm{CI}$ $\left.-0.05,0.17 ; I^{2}=92 \%, p=0.001\right)$, after $72 \mathrm{~h}$ was $-2.74(\mathrm{CI}$ $\left.-3.07,-2.42 ; I^{2}=0.0, p 0.0\right)$, and after 7 days was $-0.82(\mathrm{CI}$ $-0.19,-0.65 ; I^{2}=90.6, p=0.001$ ) (Figure 4 ).
In vital root canal subgroup analysis, SMD of single-visit treatment on pain was $-0.73\left(\mathrm{CI}-0.87,-0.58 ; I^{2}=755\right.$, $p=0.001$ ), in nonvital root canal subgroup was -0.36 (CI $\left.-0.65,-0.07 ; I^{2}=88.8 \%, p=0.001\right)$, and both root canal was $-0.23\left(\mathrm{CI}-0.29,-0.17 ; I^{2}=96 \%, p=0.001\right)$ (Figure 5).

3.5. Risk of Bias across Studies. The publication bias was shown as a funnel plot. Begg's test for small-study effects showed the $p$ value was $=0.19$; hence, there was no publication bias $(z=-0.75)$ (Figure 6). 


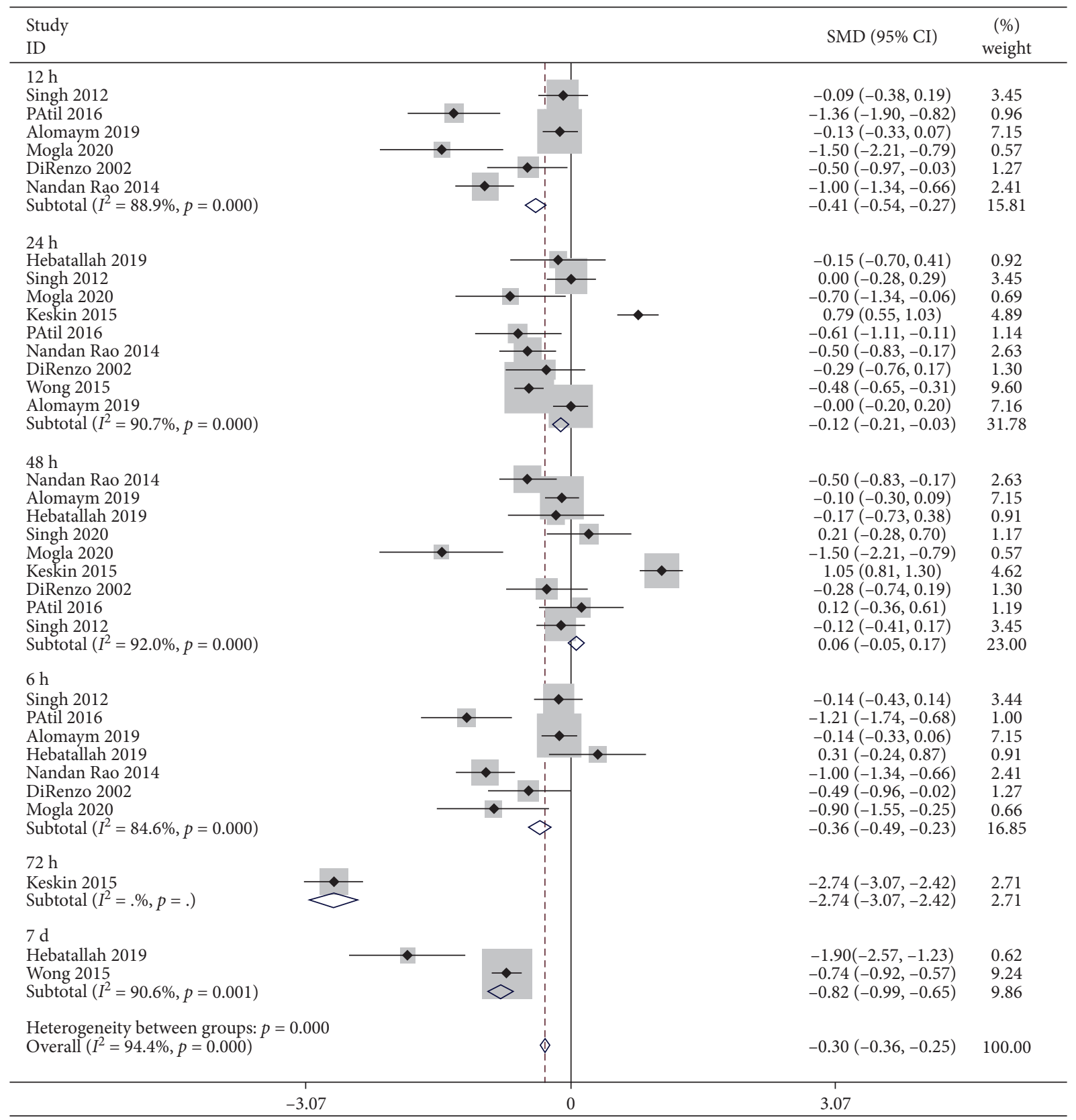

FIgURE 4: Forest plot of comparison pain in terms of follow-up time (continuous).

\section{Discussion}

The experience of postendodontic pain is one of the most common patients' complaints after root canal treatment. This symptom could affect the life quality and routine daily functions of patients. Therefore, it is important for clinicians to manage the patients' discomfort after treatment as well as pain management during RoCT [6].

The numbers of sessions for the treatment of each tooth are one of the factors that should be considered. Various studies evaluated the effects of single- and multiple-visit treatments on the experience of postendodontic by patients [41]. However, the results of these studies were not comparable due to the inconsistency in studies such as demographic differences among studied individuals, individuals' pain threshold in evaluated teeth, sample size, and different pain measurement scales $[14,42-44]$. Therefore, the current study was conducted to compare the outcomes of these studies and evaluate them.

Overall, on the basis of the available evidence, the metaanalysis showed that the risk of postoperative pain in one visit was significantly 1.02 times higher than that in the multiple-visit treatment. Subgroup analysis in terms of follow-up period and nonvital pulp affected heterogeneity but not significantly. Therefore, heterogeneity was $33.7 \%$ at 


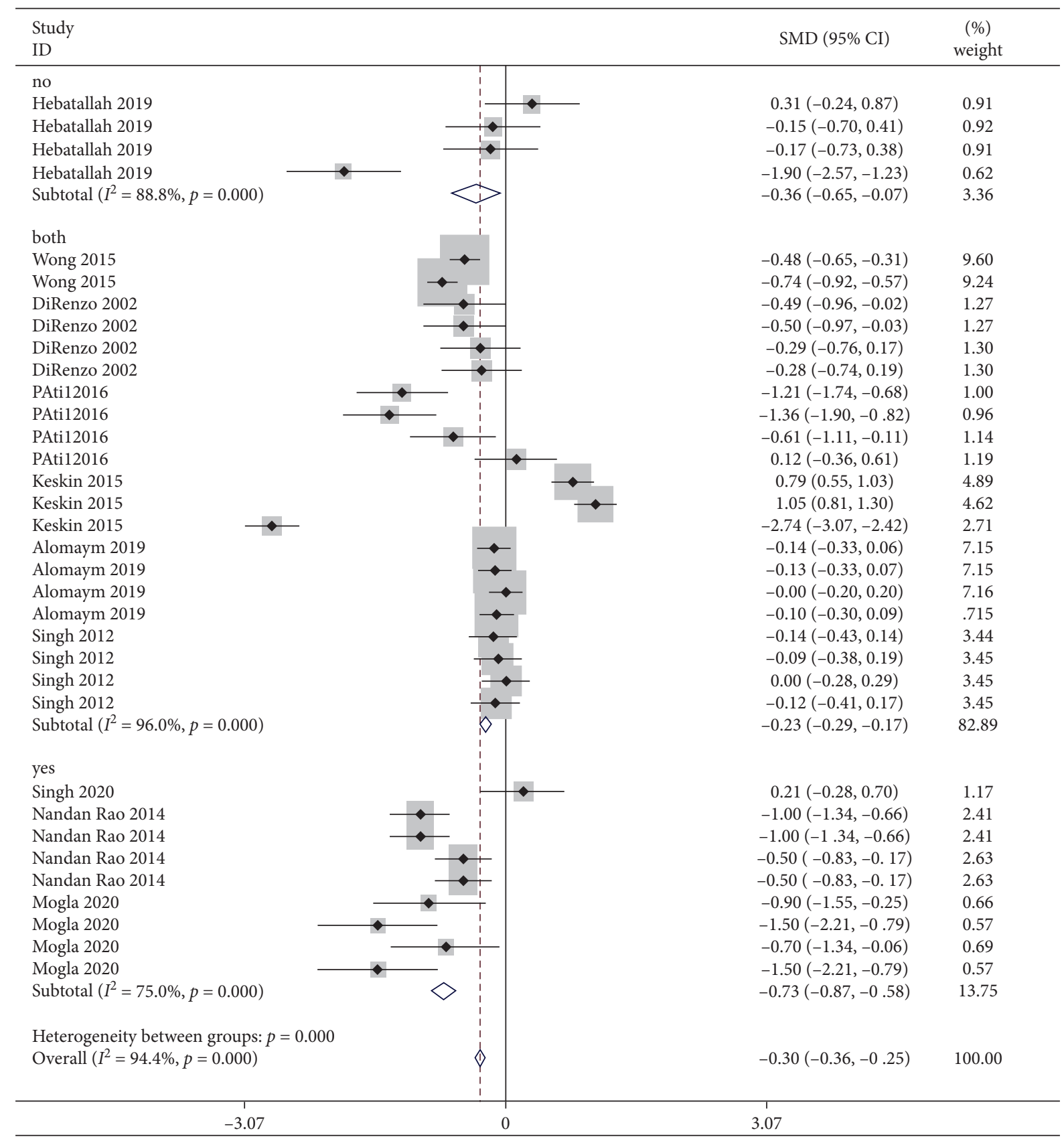

Figure 5: Forest plot of comparison pain in terms of vital/nonvital root canal (continuous).

the 7-day follow-up period, and $I^{2}=0.0 \%$ was based on necrotic teeth.

These results were inconsistent with a study conducted in 2017. Their findings suggested that based on 20 studies with 3008 teeth, the risk of postoperative pain did not significantly differ between the two single-visit versus multiple-visit treatment groups [15]. However, in their study, subgroup analysis was not performed based on the type of study, and in other subgroups, the sample size was small.

Another study in 2011 compared healing and postoperative pain of root canal treatment in single versus multiple visits in patients with infected root canals. They were recognized and reported that the healing rate of infected teeth among single- and multiple-visit root canal treatment was similar. The frequency of short-term postobturation pain after single-visit was less than that after multiple-visit root canal treatment [41]. The results of our study are not in line with the results of the above study.

There is another inconsistent systematic review that was conducted in 2008. That study included twelve randomized controlled trials after searching Cochrane Oral Health Group's Trials Register, CENTRAL, MEDLINE, and EMBASE databases for studies published until 2007 that included randomized or quasi-randomized controlled trials (RCTs). The authors evaluated the effectiveness or 


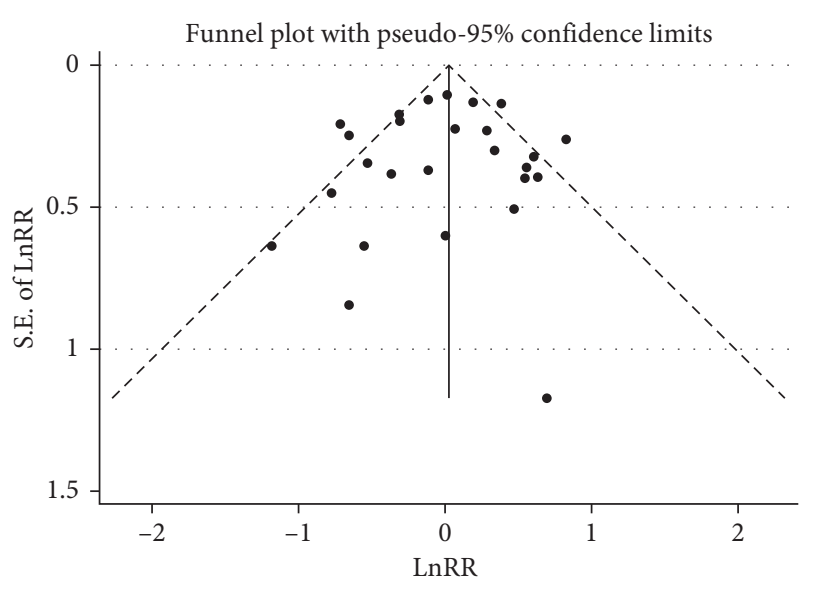

Figure 6: Risk of bias across studies.

complications of completion of root canal treatment (RoCT) in a single visit versus multiple visits, with or without medication. They reported that the frequency of immediate postoperative pain between single-visit and multiple-visit RoCT was not significantly different. However, the single-visit RoCT patient reported a higher frequency of swelling and sedative use [45]. In their study, the evidence to support the result was low, and only dichotomous data of postoperative pain were used for conclusion; whereas in our study, both continuous and dichotomous data were used for conclusion.

In another inconsistent systematic review (2009), there is no significant difference in the prevalence of postoperative pain between single- and multiple-visit root canal treatments [46]. Although, in their study, sixteen studies are used for review, type of included studies, timeline limitation, the heterogeneity index, and publication bias tests are unclear.

Manfredi et al. conducted a meta-analysis that included 25 randomized controlled trials (RCTs) and quasi-RCTs studies to evaluate the effectiveness or complications of completion of root canal treatment (RoCT) in a one visit versus multiple visits, with or without medication. The studies suggested patients in one visit might be more likely to experience pain in the first week than multiple visits [14]. The results of our study are in line with the results of Manfredi's study. In their study, only dichotomous data of postoperative pain were used for conclusion. The subgroup analysis was not performed based on the type of study, and the number of included articles in some subgroup analyses was limited.

Moreover, other characteristics were also evaluated in the current study despite postendodontic pain. There are several root canal obturation techniques; cold lateral compaction is the most used technique for root canal obturation [47]. In the current study according to available evidence, lateral compaction frequently has been used for root canal obturation by clinicians. This technique is a low-cost and simple technique that considered a reference for evaluating other obturation techniques [47].

Different irrigation solutions like $\mathrm{NaOCl}, \mathrm{EDTA}$, and normal saline are used to flush out irritants and debris from root canals [21]. In the current systematic review, it has been shown that hypochlorite $(\mathrm{NaOCl})$ was the most frequent solution used for irrigation in evaluated studies.

4.1. Strengths and Limitations. We excluded quasiexperimental studies, and analysis was carried out only on RCTs; therefore, the best quality of evidence was available. Despite the strengths of this study, the results have inherent limitations. First, significant heterogeneity was seen among the included studies. Hence, to mitigate this problem, a subgroup analysis was conducted to identify the main sources of heterogeneity. However, in some subgroups, there were limited studies and the evidence to support the result was low. Second, most of the studies in the present meta-analysis were not adjusted to some factors such as clinical conditions, tooth location, sex, bacteriologic status, and type of filling material. Therefore, these limitations may increase the possibility of bias that should be determined when interpreting these findings.

\section{Conclusions}

Overall, based on relative ratio (RR) estimates, the metaanalysis showed that the incidence of postoperative pain of the single-visit was more than that of the multiple visit treatment with acceptable statistical heterogeneity and moderate quality of the studies. However, based on the standardized mean difference (SMD) result, heterogeneity was high. For better conclusions, studies with a high sample size and long follow-up period need to be conducted.

\section{Abbreviations \\ RoCT: Root canal treatment \\ RCTs: Randomized controlled trials \\ VAS: Visual Analog Scale.}

\section{Data Availability}

All data generated or analyzed during this study are included in this published article.

\section{Conflicts of Interest}

The authors declare that they have no conflicts of interest.

\section{Authors' Contributions}

Simin Sharifi and Solmaz Maleki Dizaji contributed equally.

\section{Acknowledgments}

The authors appreciate the personnel of the Dental and Periodontal Research Center for guidance and help.

\section{References}

[1] D. Kandaswamy, N. Venkateshbabu, G. Arathi, R. Roohi, and S. Anand, "Effects of various final irrigants on the shear bond 
strength of resin-based sealer to dentin," Journal of Conservative Dentistry, vol. 14, no. 1, pp. 40-42, 2011.

[2] N. Kumar, V. Aggarwal, M. Singla, and R. Gupta, "Effect of various endodontic solutions on punch out strength of Resilon under cyclic loading," Journal of Conservative Dentistry, vol. 14, no. 4, pp. 366-369, 2011.

[3] L. B. Peters and P. R. Wesselink, "Periapical healing of endodontically treated teeth in one and two visits obturated in the presence or absence of detectable microorganisms," International Endodontic Journal, vol. 35, no. 8, pp. 660-667, 2002.

[4] M. T. Pochapski, F. A. Santos, E. D. de Andrade, and G. B. Sydney, "Effect of pretreatment dexamethasone on postendodontic pain," Oral Surgery, Oral Medicine, Oral Pathology, Oral Radiology, and Endodontology, vol. 108, no. 5, pp. 790-795, 2009.

[5] L. Beaton, R. Freeman, and G. Humphris, "Why are people afraid of the dentist? observations and explanations," Medical Principles and Practice, vol. 23, no. 4, pp. 295-301, 2014.

[6] M. J. Eghbal, A. Haeri, A. Shahravan et al., "Postendodontic pain after pulpotomy or root canal treatment in mature teeth with carious pulp exposure: a multicenter randomized controlled trial," Pain Research and Management, vol. 2020, Article ID 5853412, 14 pages, 2020.

[7] C. O. Brahm, J. Lundgren, S. G. Carlsson, P. Nilsson, J. Corbeil, and C. Hägglin, "Dentists' views on fearful patients. Problems and promises," Swedish Dental Journal, vol. 36, no. 2, pp. 79-89, 2012.

[8] R. Moore and I. Brødsgaard, "Dentists' perceived stress and its relation to perceptions about anxious patients," Community Dentistry and Oral Epidemiology, vol. 29, no. 1, pp. 73-80, 2001.

[9] F. A. Alonaizan and Y. F. AlFawaz, "Is phototherapy effective in the management of post-operative endodontic pain? a systematic review of randomized controlled clinical trials," Photodiagnosis and Photodynamic Therapy, vol. 26, pp. 53-58, 2019.

[10] F. Aksoy and B. Ege, "The effect of pretreatment submucosal injections of tramadol and dexamethasone on post-endodontic pain in mandibular molar teeth with symptomatic irreversible pulpitis: a randomized controlled clinical trial," International Endodontic Journal, vol. 53, no. 2, pp. 176-185, 2020.

[11] P. Singh, "A comparative study of flare ups in single visit and multiple visit root canal treatment," Journal of Advanced Medical and Dental Sciences Research, vol. 7, no. 4, pp. 35-37, 2019.

[12] V. Joshi, Y. Kumar, N. Jindal, and R. Aggarwal, "An in vivo comparative evaluation of postoperative complications in single- versus multiple-visit endodontic therapy: 18 month follow-up," Dental Journal of Advance Studies, vol. 07, no. 02, pp. 66-73, 2019.

[13] M. A. Alomaym, M. M. Aldohan, M. Alharbi, and N. Alharbi, "Single versus multiple sitting endodontic treatment: incidence of postoperative pain-a randomized controlled trial," Journal of International Society of Preventive and Community Dentistry, vol. 9, no. 2, p. 172, 2019.

[14] M. Manfredi, L. Figini, M. Gagliani, and G. Lodi, "Single versus multiple visits for endodontic treatment of permanent teeth," Cochrane Database of Systematic Reviews, vol. 12, no. 12, 2016.

[15] F. Schwendicke and G. Göstemeyer, "Single-visit or multiplevisit root canal treatment: systematic review, meta-analysis and trial sequential analysis," BMJ Open, vol. 7, no. 2, 2017.
[16] A. R. S. Al-Negrish and R. Habahbeh, "Flare up rate related to root canal treatment of asymptomatic pulpally necrotic central incisor teeth in patients attending a military hospital," Journal of Dentistry, vol. 34, no. 9, pp. 635-640, 2006.

[17] A. P. Verhagen, H. C. W. De Vet, R. A. De Bie et al., "The Delphi list: a criteria list for quality assessment of randomized clinical trials for conducting systematic reviews developed by Delphi consensus," Journal of Clinical Epidemiology, vol. 51, no. 12, pp. 1235-1241, 1998.

[18] A. Singh, A. Kumar, J. Nazeer, R. Singh, and S. Singh, "Incidence of postoperative flare-ups after single-visit and multiple-visit endodontic therapy in permanent teeth," Journal of Indian Society of Pedodontics and Preventive Dentistry, vol. 38, no. 1, p. 79, 2020.

[19] S. Mogla, "Assessment of post-operative pain in single versus multiple sitting root canal treatment-a clinical study," Journal of Advanced Medical and Dental Sciences Research, vol. 8, no. 8, pp. 196-198, 2020.

[20] M. Hebatallah, M. A. E. A. Saied, and S. Abeer, "Post-obturation pain following one-visit versus two-visit root canal treatment of necrotic anterior and premolar teeth using protaper next," Acta Scientific Dental Sciences, vol. 3, no. 5, pp. 64-70, 2019.

[21] Y. E. Hepsenoglu, T. F. Eyuboglu, and M. Özcan, "Postoperative pain intensity after single-versus two-visit nonsurgical endodontic retreatment: a randomized clinical trial," Journal of Endodontics, vol. 44, no. 9, pp. 1339-1346, 2018.

[22] H. EL Sheikh, M. Fawzy, M. Khalefa, and H. Bastawy, "Clinical evaluation of single versus multiple visits endodontic retreatment outcome: a randomized controlled trial," AlAzhar Dental Journal for Girls, vol. 4, no. 2, pp. 121-126, 2017.

[23] A. A. Patil, S. B. Joshi, S. V. Bhagwat, and S. A. Patil, "Incidence of postoperative pain after single visit and two visit root canal therapy: a randomized controlled trial," Journal of Clinical and Diagnostic Research, vol. 10, no. 5, pp. ZC09ZC12, 2016.

[24] A. W.-Y. Wong, C. S.-C. Tsang, S. Zhang, K.-Y. Li, C. Zhang, and C.-H. Chu, "Treatment outcomes of single-visit versus multiple-visit non-surgical endodontic therapy: a randomised clinical trial," BMC Oral Health, vol. 15, no. 1, pp. 1-11, 2015.

[25] C. Keskin, E. O. Demiryürek, and T. Özyürek, "Postoperative pain after single-versus-multiple visit root canal treatment in teeth with vital or non-vital pulps in a Turkish population," Asian Journal of Scientific Research, vol. 8, no. 3, pp. 413-420, 2015.

[26] K. N. Rao, R. Kandaswamy, G. Umashetty, V. P. Rathore, C. Hotkar, and B. S. Patil, "Post-Obturation pain following one-visit and two-visit root canal treatment in necrotic anterior teeth," Journal of International Oral Health, vol. 6, no. 2, pp. 28-32, 2014.

[27] S. Singh and A. Garg, "Incidence of post-operative pain after single visit and multiple visit root canal treatment: a randomized controlled trial," Journal of Conservative Dentistry, vol. 15, no. 4, pp. 323-327, 2012.

[28] M. Prashanth, P. N. Tavane, S. Abraham, and L. Chacko, "Comparative evaluation of pain, tenderness and swelling followed by radiographic evaluation of periapical changes at various intervals of time following single and multiple visit endodontic therapy: an in vivo study," The Journal of Contemporary Dental Practice, vol. 12, no. 3, pp. 187-191, 2011.

[29] C. Wang, P. Xu, L. Ren, G. Dong, and L. Ye, "Comparison of post-obturation pain experience following one-visit and twovisit root canal treatment on teeth with vital pulps: a randomized controlled trial," International Endodontic Journal, vol. 43, no. 8, pp. 692-697, 2010. 
[30] B. Ince, E. Ercan, M. Dalli, C. T. Dulgergil, Y. O. Zorba, and $\mathrm{H}$. Colak, "Incidence of postoperative pain after single- and multi-visit endodontic treatment in teeth with vital and nonvital pulp," European Journal of Dentistry, vol. 03, no. 4, pp. 273-279, 2009.

[31] P. A. Risso, A. J. L. A. Cunha, M. C. P. Araujo, and R. R. Luiz, "Postobturation pain and associated factors in adolescent patients undergoing one- and two-visit root canal treatment," Journal of Dentistry, vol. 36, no. 11, pp. 928-934, 2008.

[32] A. Gesi, M. Hakeberg, J. Warfvinge, and G. Bergenholtz, "Incidence of periapical lesions and clinical symptoms after pulpectomy-a clinical and radiographic evaluation of 1versus 2-session treatment," Oral Surgery, Oral Medicine, Oral Pathology, Oral Radiology, and Endodontology, vol. 101, no. 3, pp. 379-388, 2006.

[33] J. Ghoddusi, M. Javidi, M. H. Zarrabi, and H. Bagheri, "Flareups incidence and severity after using calcium hydroxide as intracanal dressing," New York State Dental Journal, vol. 72, no. 4, pp. 24-28, 2006.

[34] A. O. Oginni and C. I. Udoye, "Endodontic flare-ups: comparison of incidence between single and multiple visit procedures in patients attending a Nigerian teaching hospital," BMC Oral Health, vol. 4, no. 1, p. 4, 2004.

[35] O. Yoldas, A. Topuz, A. S. Isçi, and H. Oztunc, "Postoperative pain after endodontic retreatment: single- versus two-visit treatment," Oral Surgery, Oral Medicine, Oral Pathology, Oral Radiology, and Endodontology, vol. 98, no. 4, pp. 483-487, 2004.

[36] A. DiRenzo, T. Gresla, B. R. Johnson, M. Rogers, D. Tucker, and E. A. BeGole, "Postoperative pain after 1- and 2-visit root canal therapy," Oral Surgery, Oral Medicine, Oral Pathology, Oral Radiology, and Endodontology, vol. 93, no. 5, pp. 605-610, 2002.

[37] Z. S. M. Albashaireh and A. S. Alnegrish, "Postobturation pain after single- and multiple-visit endodontic therapy: a prospective study," Journal of Dentistry, vol. 26, no. 3, pp. 227-232, 1998.

[38] L. R. G. Fava, "A comparison of one versus two appointment endodontic therapy in teeth with non-vital pulps," International Endodontic Journal, vol. 22, no. 4, pp. 179-183, 1989.

[39] J. B. Roane, J. A. Dryden, and E. W. Grimes, "Incidence of postoperative pain after single- and multiple-visit endodontic procedures," Oral Surgery, Oral Medicine, Oral Pathology, vol. 55, no. 1, pp. 68-72, 1983.

[40] W. Soltanoff, "A comparative study of the single-visit and the multiple-visit endodontic procedure," Journal of Endodontics, vol. 4, no. 9, pp. 278-281, 1978.

[41] Y. Su, C. Wang, and L. Ye, "Healing rate and post-obturation pain of single- versus multiple-visit endodontic treatment for infected root canals: a systematic review," Journal of Endodontics, vol. 37, no. 2, pp. 125-132, 2011.

[42] N. Imura and M. L. Zuolo, "Factors associated with endodontic flare-ups: a prospective study," International Endodontic Journal, vol. 28, no. 5, pp. 261-265, 1995.

[43] Y.-L. Ng, J. P. Glennon, D. J. Setchell, and K. Gulabivala, "Prevalence of and factors affecting post-obturation pain in patients undergoing root canal treatment," International Endodontic Journal, vol. 37, no. 6, pp. 381-391, 2004.

[44] P. D. Eleazer and K. R. Eleazer, "Flare-up rate in pulpally necrotic molars in one-visit versus two-visit endodontic treatment," Journal of Endodontics, vol. 24, no. 9, pp. 614-616, 1998.

[45] L. Figini, G. Lodi, F. Gorni, and M. Gagliani, "Single versus multiple visits for endodontic treatment of permanent teeth: a
Cochrane systematic review," Journal of Endodontics, vol. 34, no. 9, pp. 1041-1047, 2008.

[46] K. Balto, "Single- or multiple-visit endodontics: which technique results in fewest postoperative problems?" Evidence-Based Dentistry, vol. 10, no. 1, p. 16, 2009.

[47] R. Krug, G. Krastl, and M. Jahreis, "Technical quality of a matching-taper single-cone filling technique following rotary instrumentation compared with lateral compaction after manual preparation: a retrospective study," Clinical Oral Investigations, vol. 21, no. 2, pp. 643-652, 2017. 